\title{
TEMA-2017: Envejecimiento y cáncer
}

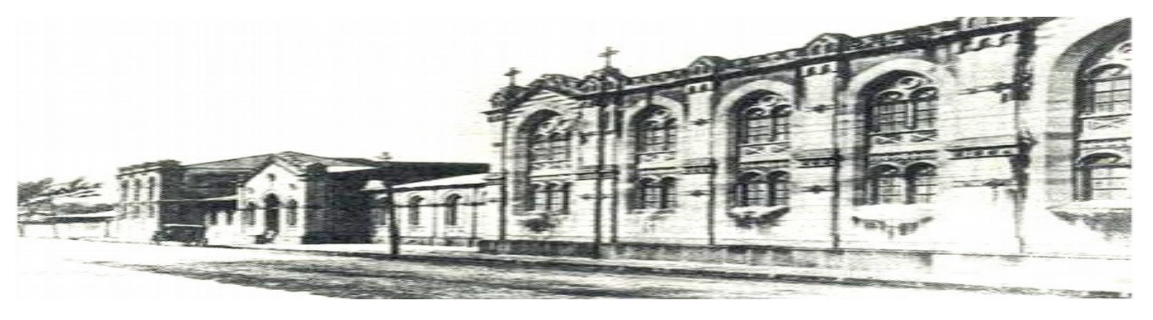

Recibido:

$18 / 05 / 2017$

Aceptado:

${ }^{1}$ Médico Asistente Especialista en Geriatría y Gerontología, Colaborador del Servicio de HematoOncología, Hospital San Juan de Dios, Caja Costarricense del Seguro Social, correo electrónico: dionisiofn@gmail.com

\section{RESUMEN}

Es bien conocido que el cáncer es un gran problema para el adulto mayor. Es la primer causa de muerte a nivel mundial según el Reporte Mundial del Cáncer del 2014. La edad es el factor de riesgo más importante para el desarrollo del cáncer. El $60 \%$ de todos los nuevos tumores malignos y el $70 \%$ de todas las muertes por cáncer ocurren en personas mayores de 65 años. En esta edad aumenta el riesgo de sufrir otras enfermedades y lesiones y puede afectar el bienestar, la independencia y la autoestima de la persona. El objetivo de este artículo es explicar de manera sencilla y detallada los cambios asociados al envejecimiento y su relación con el cáncer.

\section{PALABRAS CLAVE}

Cáncer. Senescencia. Carcinogénesis.

\section{ABSTRACT}

It is well known that cancer is a big problem for the older adult. It is the second leading cause of death followed by cardiovascular disease. Age is the most important risk factor for cancer development. $60 \%$ of all new malignancies and $70 \%$ of all cancer deaths occur in people over 65 years of age. At this age increases the risk of suffering other diseases and injuries and can affect the well-being, independence and selfesteem of the person. The aim of this article is to explain in a simple and detailed way the changes associated with aging and its relation with cancer.

\section{KEY WORDS}

Cancer. Senescence. Carcinogenesis 


\section{INTRODUCCIÓN}

El proceso de envejecimiento es muy complejo, y cada persona envejece a un ritmo diferente. Esto significa que su edad real no puede reflejar su edad fisiológica, la cual puede estimarse de acuerdo a como funciona cada organismo tanto a nivel funcional como cognitivo. La edad nunca debe ser la base para la toma de decisiones. Existen varias teorías que podrían favorecer el desarrollo de tumores en la vejez como la carcinogénesis, las alteraciones en el metabolismo, las alteraciones en el sistema inmunitario y los radicales libres ${ }^{(1)}$.

Hay que tomar en cuenta que el adulto mayor portador de cáncer tiene características diferentes comparado con otro grupo etario. $\mathrm{Y}$ eso se desarrollará en el presente documento.

\section{DISCUSIÓN}

Es un asunto complejo discutir la relación entre dos procesos la senescencia y la transformación neoplásica; ambos aún poco entendidos al día de hoy $^{(1,2)}$. La primera etapa de la carcinogénesis es la iniciación: los carcinógenos físicos o químicos, ciertos virus causan un cambio en la célula que predispone a la transformación maligna. Este cambio es irreversible.

La segunda etapa es la promoción y envuelve una fase proliferativa. Los promotores son agentes que pueden inducir la mitogénesis o la división celular en una célula iniciada. Este fenómeno incluye la activación de diversos factores de crecimiento y transcripción que promueven proliferación celular. Los investigadores creen que la cesación de fumado reduce la incidencia de cáncer comparado con aquellos que continúan fumando.

La última etapa del desarrollo del cáncer es la progresión. Esto involucra la transformación de la célula desde la fase premaligna hasta la malignidad de la misma. Las células tumorales son genéticamente mas inestables que las células normales. Otros factores pueden influir en este proceso como la habilidad de romper elementos estromales como la membrana basal y la habilidad de promover angiogénesis.
Esta claro que las alteraciones en la función regulatoria de genes: los oncogenes o los genes supresores de tumores juegan un rol importante en el desarrollo de las neoplasias. Un gran número de oncogenes han sido descritos. Un mecanismo de particular interés en el contexto de la senescencia es la muerte celular programada. La mutación de oncogenes puede afectar la reparación del (ácido desoxirribonucleico) ADN que predispone al daño celular y a la activación de oncogenes adicionales. Estos pueden ser dominantes o recesivos. Los dominantes son aquellos con alteraciones funcionales en un alelo que contribuye a un fenotipo de malignidad aún con el otro alelo normal. Los oncogenes recesivos son llamados los genes supresores de tumores, con crecimiento celular normal limitado, acelerando la apoptosis y con diferenciación celular controlada; requiere ambos alelos para ser interrumpido y contribuir al proceso de cáncer.

Existen varias teorías donde se describe que el cáncer aumenta con la edad.

1. La exposición prolongada a los carcinógenos:

Es posible que solamente por la edad esto genere el tiempo necesario para la acumulación de eventos celulares para desarrollar una neoplasia. Las mutaciones somáticas pueden generarse con una tasa aproximada de 1 en 10 divisiones celulares. Con solo el pasar del tiempo, la célula mutada llega a ser una célula maligna y subsecuentemente un tumor detectable estimado entre $10-30 \%$ de la esperanza de vida máxima en la especie animal.

2. La susceptibilidad alterada de las células envejecidas a los carcinógenos:

En este tema, la información es contradictoria. En algunos casos, la incidencia de tumores de piel en ratones producido con benzopireno ha sido relacionado a la dosis y no a la edad; otros, por ejemplo, la exposición a dimethyl benzanthracene (DMA) si están relacionados a la edad. 
3. La disminución de la habilidad para la reparación del ADN:

Es posible que el daño una vez iniciado es más difícil de reparar en células envejecidas. Varios estudios documentan que hay una disminución en la reparación del ADN secundario a la edad seguido de daño por carcinógenos como la radiación. Algunos fallos en la reparación del ADN también pueden ser reflejo de anormalidades aumentadas del cariotipo en células normales envejecidas tan bien como en los adultos mayores con enfermedad neoplásica.

4. La activación de los oncogenes o la amplificación o la disminución de la actividad de los genes supresores de tumores:

Este proceso está aumentado en el envejecimiento, resultado de aumento en la activación o la promoción o en la evolución clonal diferencial. La evidencia de esto está limitada. Dada la frecuencia de mutaciones asociadas a la edad esto genera pérdida de la función y de las alteraciones en los genes supresores de tumores.

5. Acortamiento de los telómeros y de la inestabilidad genética:

La función de los telómeros y de la enzima telomerasa están íntimamente relacionados tanto en el proceso neoplásico como en el proceso del envejecimiento. Con la edad surge el acortamiento progresivo de la porción terminal de todos los cromosomas; iniciando a partir de los 30 años y continua esta pérdida a $1 \%$ por año. Este proceso parece ser causalmente relacionado a la proliferación celular controlada $^{(3)}$.

La principal función de los telómeros es proteger la estabilidad de las secuencias de codificación interna (permitir a las células dividirse sin pérdida de los genes), la pérdida de esta función puede generar una inestabilidad cromosómica que promueve las mutaciones en secuencias de genes oncogénicos 0 genes supresores de tumores. Sin telómeros, los extremos cromosómicos podrían fusionarse y degradar el patrón genético de la célula, generando el mal funcionamiento celular, llegando a producir el cáncer o eventualmente la muerte.

La longitud de los telómeros es un predictor de la mortalidad en personas mayores de 60 años y más.

La enzima telomerasa es la responsable de añadir las repeticiones teloméricas al final de los cromosomas, eso es regenerar telómeros. Esta enzima no se expresa en las células normales, pero es activada en las células malignas.

6. Alteraciones en el microambiente:

La población mayor acumula células senescentes demostrado con la tinción de $\beta$-galactosidasa. Estas contienen altos niveles de IL-6, siendo una causa de fragilidad. Un cierto número de factores en el microambiente tumoral son importantes para el desarrollo del fenotipo de malignidad especialmente la invasión y la metástasis. Las células senescentes pueden comprometer la capacidad del tejido de renovación y secretar múltiples factores que alteran la homeostasis.

Estos factores incluyen citoquinas inflamatorias como IL-1 y con factores de crecimiento epitelial (heregulina y matriz de metaloproteinasas como $M M P-3)$ y pueden romper la arquitectura y la función del tejido circundante y estimular o inhibir la proliferación de células vecinas ${ }^{(4)}$.

Los fibroblastos humanos y en ratones senescentes aumentan la expresión del factor de crecimiento endotelial vascular y la hipoxia induce también el factor de crecimiento endotelial en las células 
envejecidas. De esta forma, las células envejecidas pueden crear un ambiente tisular que produce el sinergismo con acumulación de mutaciones para facilitar la progresión de malignidades.

7. Una disminución en la respuesta inmune $^{(4)}$ :

Esta teoría puede contribuir al aumento en el índice de malignidades. Con respecto a la inmunidad relacionada al tumor, existe la evidencia en modelos animales que hay una pérdida de la inmunidad específica del tumor asociado a la edad progresiva.

Esto incluye la capacidad del ratón envejecido para excluir los tumores, la relación cercana entre la susceptibilidad a los melanomas malignos y la disminución de la tasa de la función inmune dependiente de células $\mathrm{T}$ relacionadas a la edad, además, la habilidad de manipulación inmunofarmacológica para aumentar la función inmune y disminuir la incidencia de tumores espontáneos. La evidencia une cierta información de la deficiencia inmune asociada a la edad y aumenta la incidencia de cáncer en seres humanos.

El envejecimiento celular inhibe el cáncer mediante el arresto celular con el riesgo de transformación maligna. Por otro lado, esta senescencia puede secretar las moléculas que pueden estimular las células premalignas a formar los tumores, sugiriendo que la respuesta es antagonistamente pleiotrófica.

Una gran proporción de los cánceres son potencialmente prevenibles. Y debe evitarse la exposición al humo del cigarro, los químicos ambientales y ocupacionales, la exposición solar y ciertos factores dietéticos como el exceso de grasa, y las comidas con exceso de sal, ahumados $\mathrm{y}$ en vinagre. Si bien es cierto que los adultos mayores van adquiriendo con el tiempo exposición a varios carcinógenos, siempre hay beneficio en modificar estas costumbres y aumentar la ingesta de la fibra, las vitaminas y los vegetales frescos.
Existe evidencia del uso de tamoxifeno como agente preventivo del cáncer de mama, sin embargo, es menos efectivo en mujeres de edad avanzada. Por otro lado, la vacuna contra el virus del papiloma humano fue aprobada para usarse en edades entre 9 a 26 años de edad y no ha sido estudiado en adultos mayores.

La disminución de la proliferación celular relacionada con la edad puede favorecer o suprimir el desarrollo del cáncer

Esta disminución puede referirse a dos procesos, el primero a disminución de la tasa de proliferación celular (implica que el tiempo entre dos duplicaciones celulares aumenta con la edad) las células madre tomadas de los ratones viejos proliferan más lentamente que las células madre tomadas de los ratones jóvenes.

El segundo a un aumento en la proporción de las células replicativamente senescentes. Estas células disminuyen en el potencial proliferativo con cada célula de duplicación.

Esto significa que disminuye el número de divisiones que quedan antes de entrar en el estado de detención irreversible del crecimiento. Esta disminución se denomina a menudo como "envejecimiento replicativo"(5).

Cada tipo de disminución relacionada con la edad en la proliferación celular (es decir, disminución de la tasa de proliferación celular, así como un aumento en la proporción de células replicativamente senescentes) podría tener una influencia ambivalente sobre el riesgo de cáncer. Comportamiento biológico de los
tumores en los adultos mayores
$(6,9,10)$

Según los estudios del Instituto Nacional de Cáncer han sugerido que en varios tipos de cáncer la tasa de sobrevida a 5 años es baja cuando se trata de adultos mayores, sin embargo, esto está relacionado más a la comorbilidad del paciente y otros factores que a la edad por si misma. Hay una creencia que el cáncer puede ser más indolente en los adultos mayores. Un indicador importante de este fenómeno es la extensión de la enfermedad el día de su presentación. En cuanto al melanoma maligno, 
en los adultos mayores se ha encontrado la enfermedad en estadios avanzados con mayor profundidad de las lesiones al momento de su presentación.

Para el cáncer de mama, algunos estudios demuestran una gran proporción de adultos mayores con enfermedad metastásica al momento de su presentación ${ }^{(7)}$; mientras que para el cáncer de pulmón se ha documentado lo contrario, y se ha observado que los pacientes mayores presentan una enfermedad localizada en una mayor proporción de $\operatorname{casos}^{(8)}$. En algunos casos de los cánceres ginecológicos se presentan más tarde en el curso de la enfermedad en la presentación en individuos mayores.

Un factor biológico que puede influir en el comportamiento neoplásico en individuos mayores es el subtipo histológico del tumor. Por lo tanto, el cáncer de tiroides en general parece comportarse de manera más agresiva en la persona mayor, también es cierto que una mayor proporción de la neoplasia tiroidea se compone de el carcinoma anaplásico que en cualquier edad tiene un comportamiento más agresivo. Similarmente, para el melanoma maligno hay una alta proporción de adultos mayores con melanoma de mal pronóstico en su tipo histológico y localización al momento de su presentación.

La leucemia mieloide aguda posee un mal pronóstico en esta edad avanzada y también en el tratamiento. Comparado con los adultos jóvenes, los blastos de esta leucemia tienen baja propensión a la apoptosis cuando se induce la remisión con el tratamiento de ara-C $\mathrm{y}$ daunorrubicina. Estos hallazgos sugieren que la leucemia en el paciente anciano puede surgir de una célula madre; por lo tanto, tal paciente puede tener una capacidad disfuncional para la recuperación hematopoyética después de la quimioterapia.

Los estudios experimentales en modelos animales muestran una tasa de crecimiento y progresión del tumor en función de la edad. En estos estudios, la capacidad de detener el crecimiento del tumor depende del sistema del tumor del huésped.
La incidencia de cáncer aumenta con la edad en seres humanos, pero los patrones de distribución relacionados con la edad son diferentes para diferentes tejidos y diferentes tumores.

El envejecimiento puede aumentar o disminuir la susceptibilidad a diferentes tejidos a iniciar el proceso y usualmente facilitar la promoción y la progresión a la carcinogénesis. Ha sido demostrado que algunos cambios genéticos comunes que se sabe que ocurren en la carcinogénesis tienen un papel clave en el proceso de inmortalización (por ejemplo, el mantenimiento de los telómeros activados) Tres grandes hipótesis podrían explicar la asociación entre el cáncer y la edad lo cual se resumen a continuación $^{(6)}$.

- La carcinogénesis es un proceso el cual el producto final es el cáncer, es más probable que ocurra en personas de edad avanzada dependiendo de la acumulación de carcinógenos ambientales.

- Los tejidos envejecidos sufren cambios moleculares paralelamente a los cambios carcinogénicos tempranos.

- Los cambios relacionados con la edad en el microambiente celular incluyen inmunosenescencia que favorece el desarrollo del cáncer y su crecimiento.

Se ha sugerido que la inestabilidad de telómeros unido al envejecimiento aumenta el riesgo de cáncer. Las estrategias para la prevención del cáncer debe incluir no solo medidas para minimizar la exposición exógena a agentes carcinógenos sino también normalizar las alteraciones relacionadas con la edad.

\section{BIBLIOGRAFÍA}

1. Svetlana V. Ukraintseva, Anatoli I. Yashin. Individual Aging and Cancer Risk: How are they related? Demographic Research, Volume 9, Article 8, Pages 163-196, Published 30 october 2003.

\section{CONCLUSIONES}


2. Vladimir N. Anisimov. The relationship between aging and carcinogénesis: a critical appraisal. Critical Reviews in Oncology/Hematology 45 (2003) 277-304.

3. Wright WE, Shay JW. Telomere biology in aging and cáncer. $\mathrm{J}$ Am Geriatr Soc. 2005;53(9 Suppl):S292-S294.

4. Ershler WB, Keller ET. Age-associated increased interleukin-6 gene expression, latelife diseases, and frailty. Annu Rev Med. 2000;51:245-270.

5. Campisi J. Aging and cancer: the doubleedged sword of replicative senescence. J Am Geriatr Soc. 1997;45(4):482-488.

6. Cohen HJ. Biology of aging as related to cancer. Cancer. 1994;74 (7 Suppl):20922100

7. Crivellari D, Aapro M, Leonard R. Breast cancer in the elderly. J Clin Oncol. 2007;25(14):1882-1890.

8. Gridelli C, Langer C, Maione P, Rossi A, Schild SE. Lung cancer in the elderly. J Clin Oncol. 2007;25(14):1898-1907.

9. Heflin MT, Cohen HJ. Cancer screening in the elderly. Hosp Pract (Minneap). 2001;36(3):61-69.

10. Hurria A, Gupta S, Zauderer M. Developing a cancer-specific geriatric assessment: a feasibility study. Cancer. 2005;104(9):19982005.

\section{CONFLICTO DE INTERÉS Y/O AGRADECIMIENTOS}

El autor declara que no existió ningún conflicto de interés en la presente revisión. 